\title{
POLAROGRAPHIC BEHAVIOR AND DETERMINATION OF 1,1-DIMETHYL-3-PHENYLTRIAZENE
}

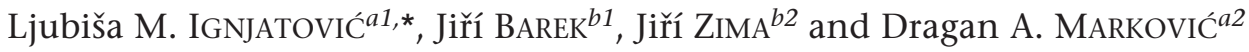 \\ ${ }^{a}$ Faculty of Physical Chemistry, University of Belgrade, P.O. Box 137, \\ 11001 Belgrade, Serbia; e-mail: ${ }^{1}$ ljignjatovic@ffh.bg.ac.yu, ${ }^{2}$ skiper@isp.b92.net \\ ${ }^{b}$ Charles University Prague, Faculty of Science, Department of Analytical Chemistry, \\ UNESCO Laboratory of Environmental Electrochemistry, Hlavova 2030, 12843 Prague 2, \\ Czech Republic; e-mail: ${ }^{1}$ barek@natur.cuni.cz, ${ }^{2}$ zima@natur.cuni.cz
}

Received November 22, 2006

Accepted April 6, 2007

Polarographic behavior of the genotoxic substance 1,1-dimethyl-3-phenyltriazene was investigated and optimum conditions were found for its determination by sampled direct current polarography and differential pulse polarography at a static mercury drop electrode in the concentration range from $1 \times 10^{-4}$ to $1 \times 10^{-7} \mathrm{~mol} \mathrm{I}^{-1}$. It was established that for reduction of the triazene group four electrons are required resulting in the formation of amino and hydrazo compound. The resulting products were identified, and the reduction pathway was proposed.

Keywords: Triazenes; Polarography; Electroreductions; Reduction mechanism; Carcinogens.

1,1-Dimethyl-3-phenyltriazene and its $0-, \mathrm{m}$ - and $\mathrm{p}$-substituted derivatives rank among genotoxic substances that also exhibit cancerostatic activity ${ }^{1,2}$. Therefore, there is an increasing demand for sensitive analytical methods for the determination of these substances.

They can be determined spectrophotometrically in the ultraviolet region ${ }^{3}$ and also via their protolysis followed by azo coupling of the arenediazonium salt formed with $\mathrm{N}$-ethyl-1-naphthylamine to form an azo dye, which can be determined photometrically in the visible region ${ }^{4}$.

Considering the fact that triazene group is polarographically active ${ }^{5}$, direct current polarography has been used to study 1,1-dimethyl-3-phenyltriazene ${ }^{6}$ and its derivatives ${ }^{4}$. More sensitive techniques, such as differential pulse polarography ${ }^{7-9}$ and adsorptive stripping voltammetry ${ }^{9-11}$ have been used for the determination of variously substituted derivatives of 1,1-dimethyl-3-phenyltriazene.

In the present paper, an attempt was made to improve the sensitivity of polarographic determination of 1,1-dimethyl-3-phenyltriazene by sampled 
direct current polarography (SDCP) and differential pulse polarography (DPP) at a static mercury drop electrode (SMDE). On the basis of polarographic, coulometric, spectrophotometric and chromatographic measurements, the mechanism of the electrochemical reduction of the triazene was investigated and the corresponding reduction scheme was postulated.

\section{EXPERIMENTAL}

\section{Reagents}

The purity of the prepared 1,1-dimethyl-3-phenyltriazene ${ }^{12}$ was checked by thin-layer chromatography, HPLC and elemental analysis. A stock standard solution of this substance $\left(1 \times 10^{-3} \mathrm{~mol} \mathrm{I}^{-1}\right)$ was prepared by dissolving a precisely weighed amount of the substance in methanol (analytical-reagent grade, Fluka). A more dilute solution $\left(1 \times 10^{-4} \mathrm{~mol} \mathrm{I}^{-1}\right)$ was prepared by dilution of the stock solution with methanol. All solutions were stored in the dark. Spectrophotometric study of the stability of the stock solutions demonstrated that the stock standard solution was stable for at least two months, while the more dilute solution was prepared weekly.

Britton-Robinson (BR) buffers were prepared in the usual way (i.e., by mixing a solution of $0.04 \mathrm{~mol} \mathrm{I}^{-1}$ orthophosphoric acid, acetic acid and boric acid with the appropriate amount of $0.2 \mathrm{~mol} \mathrm{I}^{-1}$ sodium hydroxide solution). All the chemicals used were of analyticalreagent grade, obtained from Merck.

Deionized water, produced by an UItra Clear basic SG Water apparatus (SG Wasseraufbereitung $\mathrm{GmbH}$, Germany) was used in all experiments.

\section{Apparatus}

Polarographic measurements were carried out using a PA 4 polarographic analyzer with an SMDE 1 static mercury drop electrode (both from Laboratorní př́stroje, Praha, Czech Republic). The capillary employed had an internal diameter of $0.136 \mathrm{~mm}$; the maximum drop size, obtained by opening the electromagnetic valve for $160 \mathrm{~ms}$, was used. The threeelectrode system was completed with a platinum rod auxiliary electrode and a saturated calomel reference electrode (SCE), to which all the potentials are referred to. The measurements were performed at a sweep rate of $5 \mathrm{mV} \mathrm{s}^{-1}$ and an SMDE drop time of $1 \mathrm{~s}$. A pulse amplitude of $-100 \mathrm{mV}$ was employed in DPP.

The linear scan voltammetric and cyclic voltammetric (LSV and CV) measurements were performed using the same apparatus and reference and auxiliary electrodes. For this purpose, SMDE 1 electrode was used in the hanging mercury drop electrode mode (HMDE) with the same drop size.

Constant-potential coulometric (CPC) measurements were performed using a PAR 173 potentiostat with a PAR 179 digital coulometer (Both from Princeton Applied Research, U.S.A.). The mercury pool was used as the cathode, with an SCE as reference and platinum gauze as counter electrode. The cathodic and anodic compartments were separated with a sintered glass diaphragm.

Spectrophotometric measurements were carried out on a Varian Cary 17D UV/VIS spectrophotometer (Varian Inc., U.S.A.) in 10-mm quartz cuvettes. 
HPLC measurements were performed in an isocratic system consisting of a model 2250 serial dual piston pump, 4110 VarioTherm column thermostat, DG-1310 solvent degasser and Lambda 1010 UV-VIS spectrophotometric detector with a flow cell optical path length of $10 \mathrm{~mm}$ and volume $10 \mu \mathrm{l}$ (all from Bischoff Chromatography GmbH, Germany). A Rheodyne 7725i sample injector with $10 \mu \mathrm{l}$ sample loop (Rheodyne LLC, U.S.A.) was used. The reversed-phase column ProntoSil C18 AQ with the pore size $200 \AA$ and particle size of $5 \mu \mathrm{m}$ was used (Bischoff Chromatography $\mathrm{GmbH}$, Germany). As suitable mobile phase, a mixture of aqueous $0.1 \mathrm{~mol} \mathrm{I}^{-1}$ sodium acetate with methanol $(6+4)$ was used; the flow rate was $0.3 \mathrm{ml} \mathrm{min}-1$. The UV detection was performed at 278 as well as at $230 \mathrm{~nm}$.

A Metrohm $744 \mathrm{pH}$ meter (Metrohm Ltd., Switzerland) equipped with a combined glass $\mathrm{pH}$ electrode and temperature sensor was used for $\mathrm{pH}$ measurements.

\section{Procedures}

Mixed BR buffer-methanol medium was used as the supporting electrolyte in order to ensure the solubility of the investigated substance. The actual $\mathrm{pH}$ of the BR buffer-methanol mixture $(1+1)$ was measured with a combined $\mathrm{pH}$ electrode calibrated using acetate, borate and phosphate buffers in $50 \%$ methanol $^{13}$. The $\mathrm{pH}$ value of the BR buffer-methanol mixture containing 10 vol.\% of methanol was measured with a $\mathrm{pH}$ electrode calibrated using aqueous buffers ${ }^{14}$.

A $10-\mathrm{ml}$ aliquot of an appropriate supporting electrolyte solution was placed in a voltammetric cell and deaerated for $5 \mathrm{~min}$ with nitrogen. The voltammetric cell was flushed with nitrogen passed successively through a solution of chromium(II) ions in dilute hydrochloric acid containing heavily amalgamated zinc granules, distilled water, molecular sieves and, finally, through a solution having the same solvent and supporting electrolyte composition as the test solution. After recording the baseline, the required amounts of the stock solution of the investigated substance were added and the polarograms or voltammograms were recorded.

The calibration curves were measured in triplicate and evaluated by the least-square linear regression method. The determination limit was calculated as ten times the standard deviation for ten determinations of the analyte at a concentration corresponding to the lowest point of the appropriate calibration graph ${ }^{15}$.

In the coulometric determination of the number of electrons exchanged, $20 \mathrm{ml}$ of the supporting electrolyte were placed in the coulometric cell and bubbled with nitrogen, with simultaneous initiation of pre-electrolysis at a selected constant potential. After about $20 \mathrm{~min}$, when the residual current value dropped below $0.1 \mathrm{~mA}$ and no longer changed, the circuit parameters were adjusted for automatic residual current compensation. An aliquot of the stock solution of the tested substance was then added and reduction was carried out at a constant potential with constant stirring and bubbling with nitrogen. The electrolysis was terminated when the current decreased to the residual value and the passed charge was determined by electronic integration. The reduction was also followed spectrophotometrically, polarographically and chromatographically. In the measurements, the samples were taken prior to start of the coulometric reduction and after reduction of $25,50,75$ and $100 \%$ of the triazene.

All the measurements were performed at laboratory temperature $\left(20 \pm 1^{\circ} \mathrm{C}\right)$. 


\section{RESULTS AND DISCUSSION}

Effect of $\mathrm{pH}$ on the Polarographic Behavior of 1,1-Dimethyl-3-phenyltriazene

Within the investigated range of $\mathrm{pH}$ values of the supproting electrolyte, 1,1-dimethyl-3-phenyltriazene (DPT) yields one polarographic wave (Fig. 1), i.e. one differential pulse polarographic peak (Fig. 2). Half-wave potential $E_{1 / 2}$ and the potential of DPP peak $E_{p}$ shift towards negative values with increasing $\mathrm{pH}$ of the supporting electrolyte, the resulting $\mathrm{E}_{1 / 2}-\mathrm{pH}$ and $\mathrm{E}_{\mathrm{p}}-\mathrm{pH}$ dependences having asymptotic character (Fig. 3). Those two characteristic potentials differ, at the given $\mathrm{pH}$, by $50 \mathrm{mV}$, which corresponds to the half amplitude of the superimposed pulse. The fact that $E_{1 / 2}$ and $E_{p}$ shift towards negative values with increasing $\mathrm{pH}$ indicates that protons are involved in the reduction process ${ }^{16}$.

At $\mathrm{pH}>7.0$, the sampled DC polarographic waves and DPP peaks decrease with increasing $\mathrm{pH}$ and they completely disappear at $\mathrm{pH}>11.0$. At $\mathrm{pH}<5.5$, the current of polarographic waves decreases with time. The observed time dependence of polarographic currents is associated with hydrolytic decomposition of the investigated substance ${ }^{17}$.

The linear dependence of natural logarithm of limiting current In $\mathrm{I}_{1}$ on time in buffered acid medium indicates that this hydrolysis is a first-order

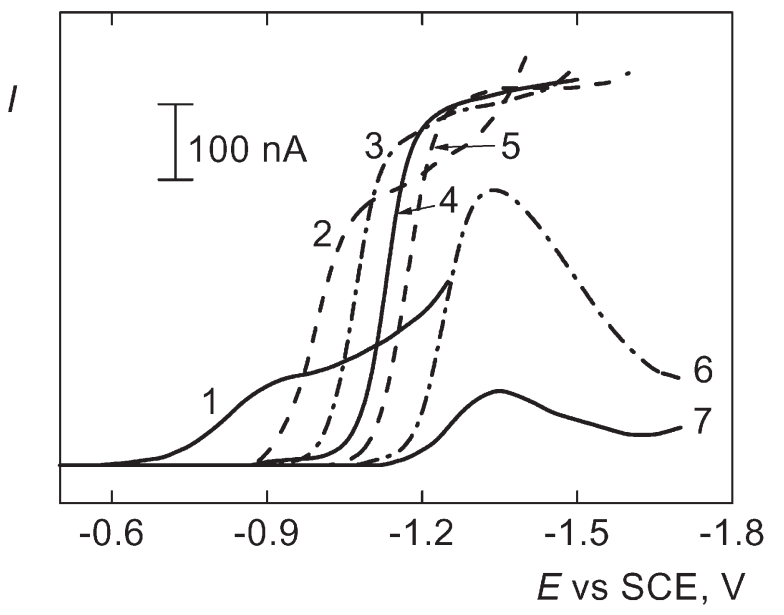

FIG. 1

Selected sampled DC polarograms of DPT $\left(4 \times 10^{-5} \mathrm{~mol} \mathrm{I}^{-1}\right)$ in mixed BR buffer-methanol (1:1) medium at $\mathrm{pH} 2.80$ (1), 4.10 (2), 5.00 (3), 5.90 (4), 6.50 (5), 8.01 (6) and 9.30 (7) 


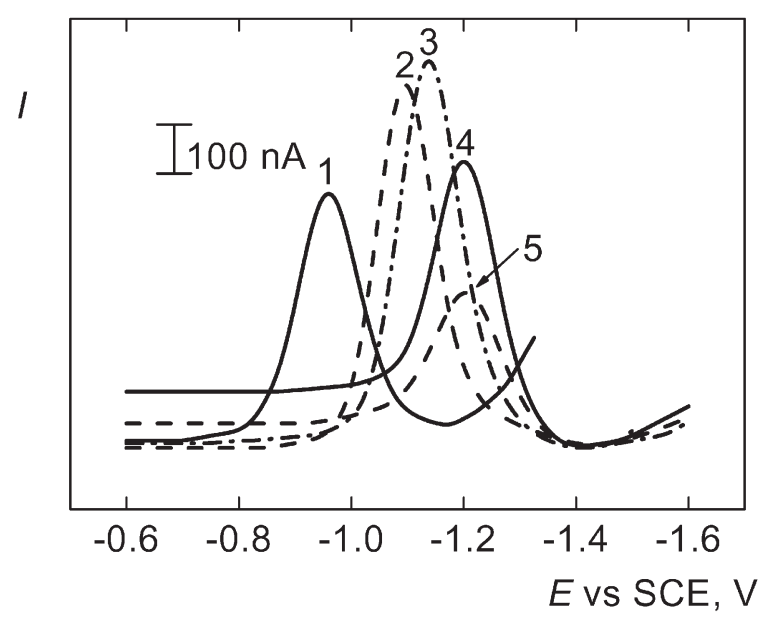

FIG. 2

DP polarograms of DPT $\left(4 \times 10^{-5} \mathrm{~mol}^{-1}\right)$ in mixed BR buffer-methanol (1:1) medium at $\mathrm{pH}$ $4.10(1), 5.90(2), 6.50(3), 8.01(4)$ and $8.70(5)$

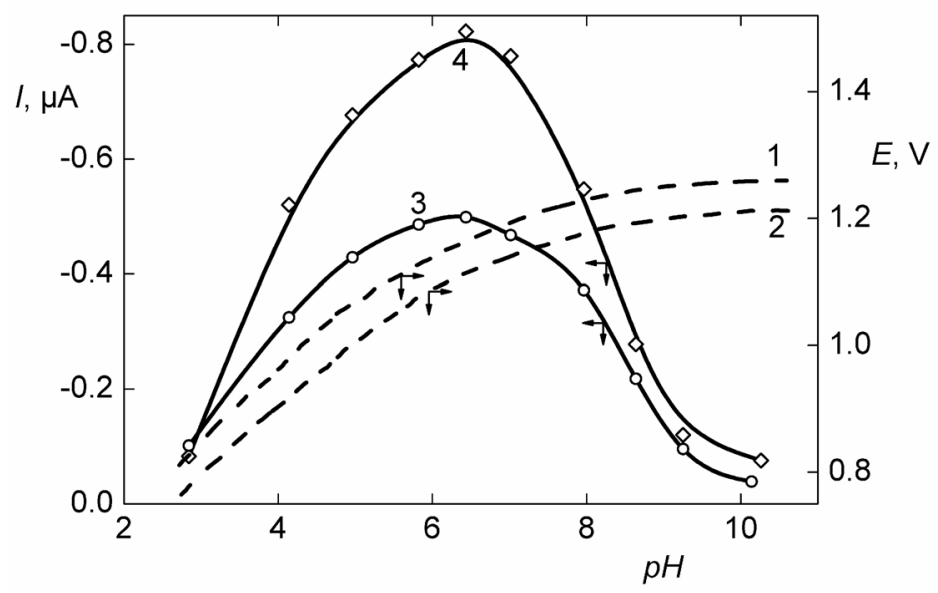

FIG. 3

The influence of $\mathrm{pH}$ of the supporting electrolyte on the half-wave potential $\mathrm{E}_{1 / 2}$ (1), DPP peak potential $E_{p}(2)$, the limiting current $I_{I}(3)$ and DPP peak current $I_{p}(4)$ of DPT $\left(4 \times 10^{-5} \mathrm{~mol} \mathrm{I}^{-1}\right)$ 
pseudomonomolecular reaction. During the decomposition of DPT, no new polarographically active species appear, which enables a continual SDC polarographic monitoring of this process. At pH 4.1, the rate constant of DPT hydrolysis, at the temperature $20^{\circ} \mathrm{C}$, amounts to $4.27 \times 10^{-2} \mathrm{~min}^{-1}$, while the activation energy determined on the basis of the dependence $\ln \mathrm{k}=$ $\mathrm{f}\left(\mathrm{T}^{-1}\right)$, with in the temperature range $10-40{ }^{\circ} \mathrm{C}$, amounts to $87 \pm 1 \mathrm{~kJ} \mathrm{~mol}^{-1}$.

It can be seen from Fig. 4 a that in BR buffer with $50 \%$ methanol $(\mathrm{pH} 4.1)$ DPT yields 3 intensive absorption bands at $\lambda_{1}=304 \mathrm{~nm}(\log \varepsilon=4.076), \lambda_{2}=$ $282 \mathrm{~nm}(\log \varepsilon=4.102)$ and $\lambda_{3}=222 \mathrm{~nm}(\log \varepsilon=3.954)$, which is in accordance with the measurements in ethanol as a solvent ${ }^{3,4}$. During the hydroIytic reaction, absorption of the $304 \mathrm{~nm}$ band decreased. Considering that this band is due to $\pi-\pi^{*}$ electronic transition of the triazene grouping, the decrease in its intensity indicates the disappearance of this chromophore, i.e. of the triazene grouping. The $\pi-\pi^{*}$ absorption band at $282 \mathrm{~nm}$ shifts during the hydrolysis of DPT towards lower wavelengths, occupying the position at $\lambda_{2}{ }^{\prime}=270 \mathrm{~nm} 30 \mathrm{~min}$ after the beginning of the reaction, with logarithm of molar absorption coefficient $\log \varepsilon=3.954$. The absorption band of DPT at $\lambda_{2}=282 \mathrm{~nm}$ is a consequence of the $\pi-\pi^{*}$ electronic transition of $\pi$ electrons of aromatic ring, additionally stabilized by delocalization with $\pi$ electrons of the triazene bonding. The hypsochromic shift of this band

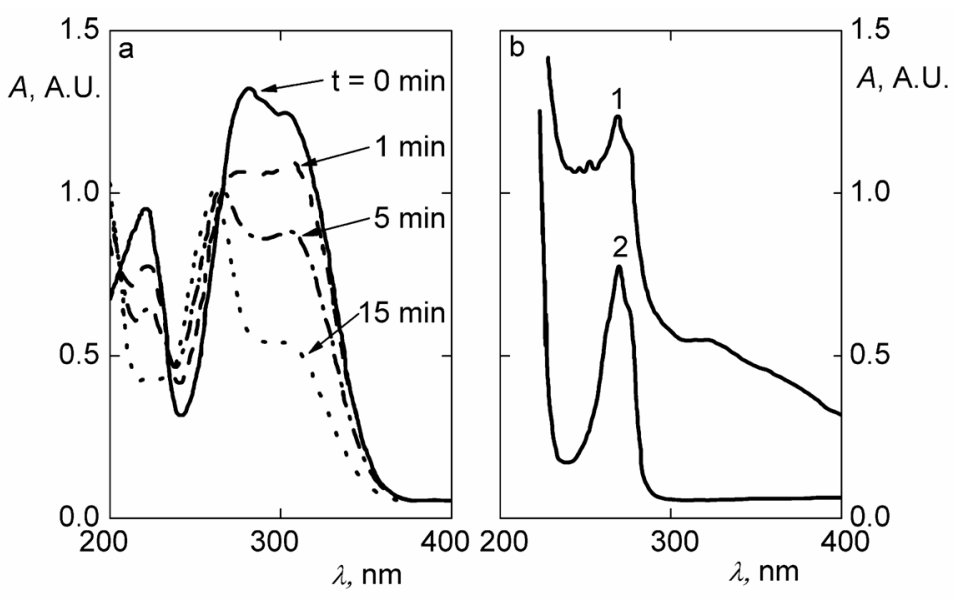

FIG. 4

UV spectrophotometric monitoring of DPT $\left(1 \times 10^{-4} \mathrm{~mol} \mathrm{I}^{-1}\right)$ degradation, $\mathrm{pH}$ 4.10. a Monitoring the reaction at room temperature; $\mathrm{b} 6 \mathrm{~h}$ after the beginning of the reaction: product of DPT decomposition (1), phenol (2) 
of $12 \mathrm{~nm}$, indicates discontinuation of the additional stabilization by delocalization, i.e. it is one more indication of triazene bonding break. The product of DPT hydrolysis recorded $6 \mathrm{~h}$ after the beginning of the reaction displays a band at $270 \mathrm{~nm}(\log \varepsilon=3.236)$. UV absorption spectrum of phenol, recorded under the same conditions, also yields a band at $270 \mathrm{~nm}$ ( $\log \varepsilon=3.236)$ which implies that one of the reaction products is phenol.

On the basis of the obtained results and of the behaviour of similar compounds ${ }^{17}$, it may be concluded that the DPT hydrolysis in the used buffer medium proceeds as acid-catalyzed, with a complex rate constant $\mathrm{k}_{\text {tot }}=$ $\mathrm{k}_{2} \mathrm{k}_{1} / \mathrm{k}_{-1}$ and according to the reaction scheme shown in Fig. 5.

At $\mathrm{pH}$ values above 9.5, $\mathrm{E}_{1 / 2}$ and $\mathrm{E}_{\mathrm{p}}$ do not change. The obtained dependences may be approximated by tangents ${ }^{18}$ intersecting at $\mathrm{pH}$ 9.5, which is the experimentally (polarographically) determined $\mathrm{pK}_{a}$ value of DPT. At pH values below $\mathrm{pK}_{\mathrm{a}}=9.5$, DPT exists in the acid form, while at $\mathrm{pH}$ of the supporting electrolyte higher than 9.5 , its conjugated alkaline form predominates in the solution.

The nontypical SDC polarograms of DPT obtained in the $\mathrm{pH}$ range of the supporting electrolyte 8.0-11.0 are associated with the presence of methanol and with its influence on the preliminary protonation of electroactive species. The fact that, within this $\mathrm{pH}$ range, the slope of the $\mathrm{E}_{1 / 2}-\mathrm{pH}$ dependence does not correspond to the relation $\mathrm{dE} / \mathrm{dpH}=-2.303 \mathrm{mRT} / \alpha \mathrm{n}_{\mathrm{a}} \mathrm{F}$ indicates ${ }^{19}$ that a substance adsorbed on the electrode surface is subjected to protonation prior to the electrode reduction. With increasing methanol content, the rate of the preceding protonation reaction decreased for two reasons: due to a lower constant rate of protonation and due to a decreased adsorption of the investigated triazene. The observed decrease in the limiting current (and the current beyond the DP polarographic peak) in the region around $-1.6 \mathrm{~V}$ at $\mathrm{pH}>7.5$ is associated with the decrease in the rate of surface protonation as a consequence of desorption of the investigated sub-

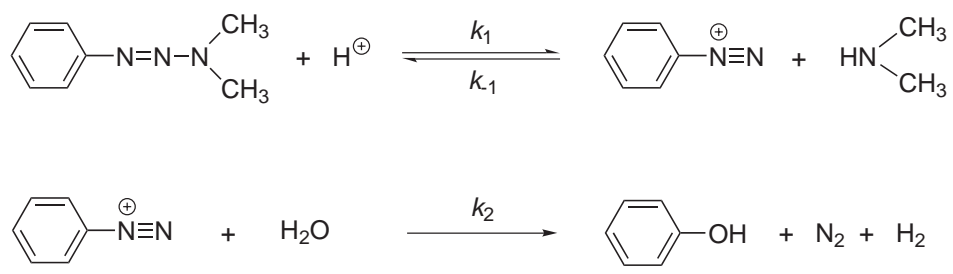

FIG. 5

The reaction scheme of 1,1-dimethyl-3-phenyltriazene decomposition in acidic medium 
stance at potentials much more negative than the potential of electrocapillary maximum, where maximal adsorption of uncharged molecules of the investigated substance is expected ${ }^{20}$.

\section{The Electrode Reduction Mechanism}

From the logarithmic analysis of SDC polarograms it follows that the electrode process is irreversible. The irreversible character of the electrode reduction of DPT is also confirmed by cyclic voltammetric measurements using the hanging mercury drop as the working electrode; no anodic peak was obtained at any $\mathrm{pH}$ value of the supporting electrolyte and at any polarization rate of the working electrode (Fig. 6), which indicates that the products of DPT reduction are not oxidized at the mercury electrode. The absence of anodic peak is one of the main criteria for the establishment of electrode process irreversibility ${ }^{21}$. At $\mathrm{pH}$ 6.5, the potential of cathodic CV peak shifts towards more negative values with increasing scan rate, which also confirms the irreversible character of the electrode process.

The values of $\alpha \mathrm{n}_{\mathrm{a}}$ for DPT electrochemical reduction increase with increasing $\mathrm{pH}$ of the supporting electrolyte to 5.9 and 7.1, and decrease afterwards, which leads to the conclusion that the coefficient of electron transition through the energy barrier of double electric layer is the highest

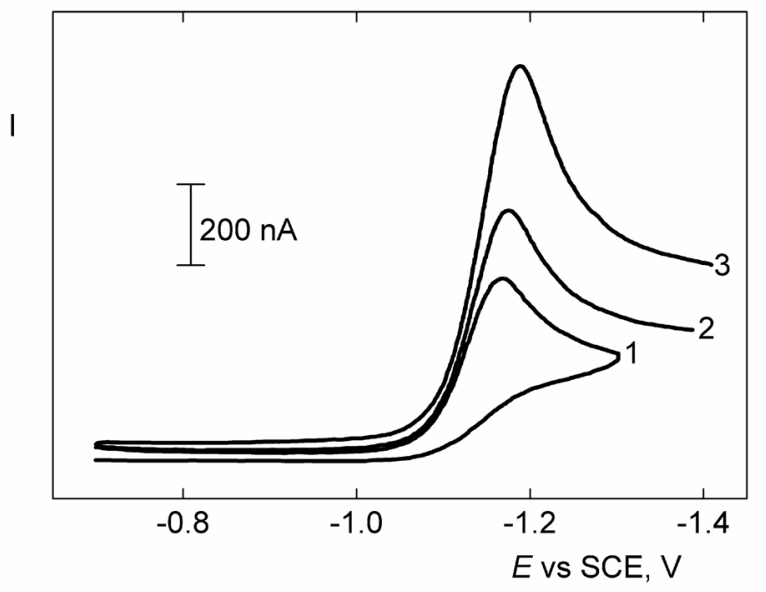

FIG. 6

Linear voltammograms of DPT $\left(4 \times 10^{-5} \mathrm{~mol} \mathrm{I}^{-1}, \mathrm{pH} 6.50\right)$ at various polarization rates (in $\left.\mathrm{mV} \mathrm{s}^{-1}\right)$ : $10(1), 20(2)$ and $50(3)$ 
at $\mathrm{pH} 6.5\left(\alpha \mathrm{n}_{\mathrm{a}}=1.13\right)$. The values of $\alpha \mathrm{n}_{\mathrm{a}}$ can also be determined from the dependence of DPT CV peak potential $E_{p}$ (in $\mathrm{mV}$ ) on the logarithm of potential scan rate $v$ (in $\mathrm{mV} \mathrm{s}^{-1}$ ) of the working electrode ${ }^{22}$. The experimentally obtained straight-line dependence $(r=0.9981)$ may be represented by the equation

$$
-E_{p}=1146+0.019 \log v \text {. }
$$

On the basis of the slope of the straight line the value of $\alpha n_{a}=1.12$ is calculated for $\mathrm{pH}$ 6.5, which is in quite good correlation with the results obtained from sampled DC polarographic measurements.

Voltammetric reduction of DPT is controlled by the diffusion of electroactive species as the slowest step in the electrochemical process. The diffusion nature of the voltammetric peak of DPT is confirmed on the basis of linear dependence ${ }^{22}$ of $\mathrm{CV}$ peak current $\mathrm{I}_{\mathrm{p}}$ on the square root of polarization rate $v^{1 / 2}$ : a linear dependence $\log I_{p}=f(\log v)$ with $r=0.9991$, with the slope of 0.495 was obtained.

On the basis of the calculated and cited values of $\alpha \mathrm{n}_{\mathrm{a}}$ (1.12 at $\mathrm{pH} 6.5$ ), taking also into consideration that 4 electrons participate in the reduction process (which will be explained bellow), the value of the diffusion coefficient of DPT in the given medium was calculated $1.25 \times 10^{-5} \mathrm{~cm}^{2} \mathrm{~s}^{-1}$. This value is in good agreement with the value of the diffusion coefficient calculated according to the Ilkovic equation (for diffusion-controlled fourelectron process) $1.20 \times 10^{-5} \mathrm{~cm}^{2} \mathrm{~s}^{-1}$.

The number of electrons participating in the DPT reduction on mercury electrode was determined by coulometry at a constant potential of $-1.300 \mathrm{~V}$, which corresponds to the limiting current of the polarographic wave of the investigated substance. By coulometric analysis it was established that electrode reduction takes place with the participation of 4 electrons per one molecule of DPT. Limiting currents of SDC polarographic waves linearly decreased with increasing of the percentage of reduced substance recalculated for the number of electrons, n, per one molecule of DPT (Fig. 7), which indicates that there is no other secondary process consuming the charge $\mathrm{e}^{23}$ and the result showing the participation of 4 electrons per one DPT molecule can be considered as reliable.

UV absorption spectrum of DPT at pH 6.5 (Fig. 8, curve 1) yields three intensive absorption bands with the following parameters: $\lambda_{1}=306 \mathrm{~nm}(\log \varepsilon=$ 3.980), $\lambda_{2}=282 \mathrm{~nm}(\log \varepsilon=3.957)$ and $\lambda_{3}=222 \mathrm{~nm}(\log \varepsilon=3.854)$. The product of DPT electrolysis (Fig. 8, curve 2) has two absorption maxima with $\lambda_{1}=278 \mathrm{~nm}(\log \varepsilon=3.041)$ and $\lambda_{2}=229 \mathrm{~nm}(\log \varepsilon=3.833)$. During 


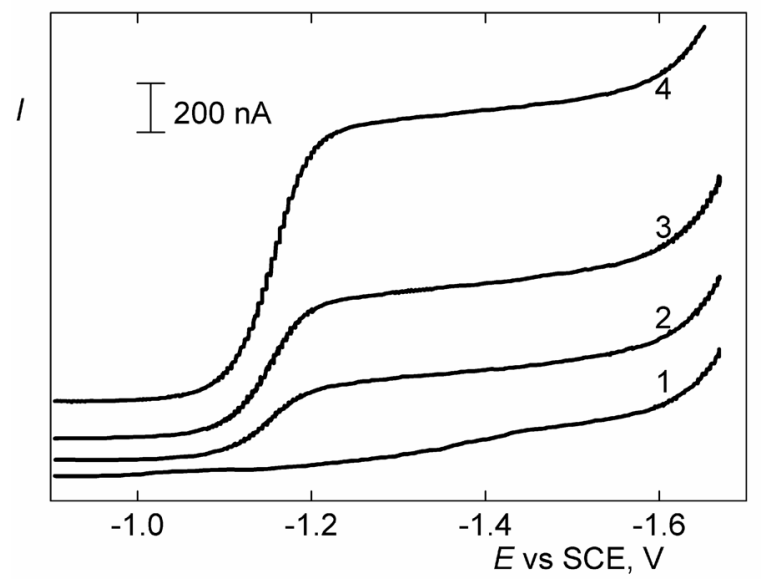

FIG. 7

SDC polarograms of DPT $\left(1 \times 10^{-4} \mathrm{~mol} \mathrm{I}^{-1}, \mathrm{pH} 6.50\right)$ after passage of charge corresponding to $\mathrm{n}=$ $0(1), 2(2), 3(3)$ and $4(4)$

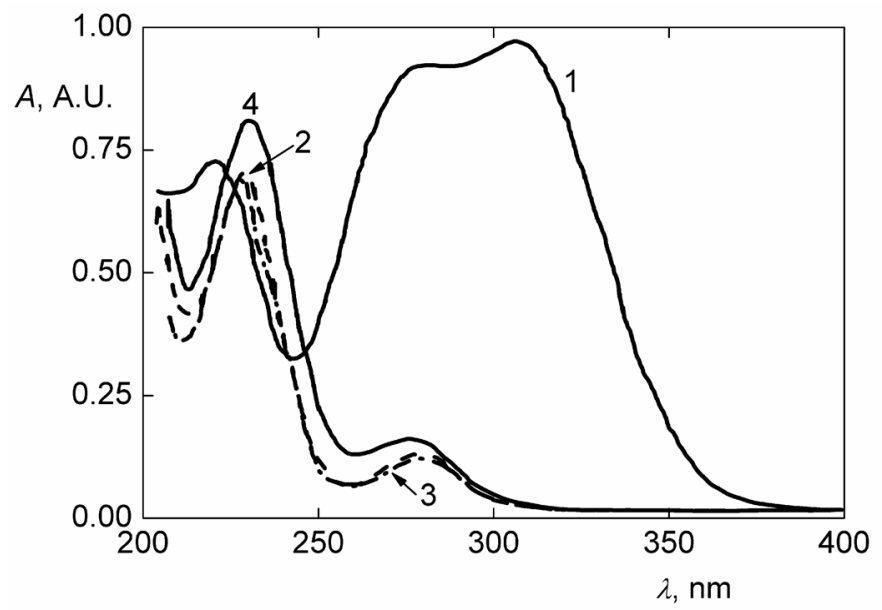

FIG. 8

UV absorption spectra: DPT (1), product of DPT electrolysis (2), aniline (3) and phenylhydrazine (4). Solvent: BR buffer-methanol (1:1) $\mathrm{pH} 6.50$; concentration of the measured substances $1 \times 10^{-4} \mathrm{~mol} \mathrm{I}^{-1}$ 
electrolysis, the absorption band of DPT at $306 \mathrm{~nm}$ disappears, which is a consequence of reduction of the triazene double bond as a chromophore.

The obtained UV absorption spectrum of the product of DPT reduction is similar to the spectra of aniline and phenylhydrazine (Fig. 8, curves 3 and 4). The characteristics of aniline and phenylhydrazine spectra in the $\mathrm{pH} 6.5$ buffer are as follows: aniline has two absorption maxima at $\lambda_{1}=280 \mathrm{~nm}$ $(\log \varepsilon=3.000)$ and $\lambda_{2}=227 \mathrm{~nm}(\log \varepsilon=3.839)$, phenylhydrazine has also two absorption maxima at $\lambda_{1}=276 \mathrm{~nm}(\log \varepsilon=3.173)$ and $\lambda_{2}=232 \mathrm{~nm}$ $(\log \varepsilon=3.900)$. It is clear that it is not possible to identify the DPT electrolysis products with certainty only on the basis of UV absorption spectra. For that reason, additional HPLC measurements were carried out yielding chromatograms of DPT electrolysis product (Fig. 9, chromatogram d) and the mixture of aniline and phenylhydrazine at various concentrations (Fig. 9, chromatograms a-c). UV detector was adjusted to the wavelength $278 \mathrm{~nm}$, so it could detect all the substances of interest. Aniline in the obtained chromatograms yields a peak with the retention time $5.9 \mathrm{~min}$, and phenyl-

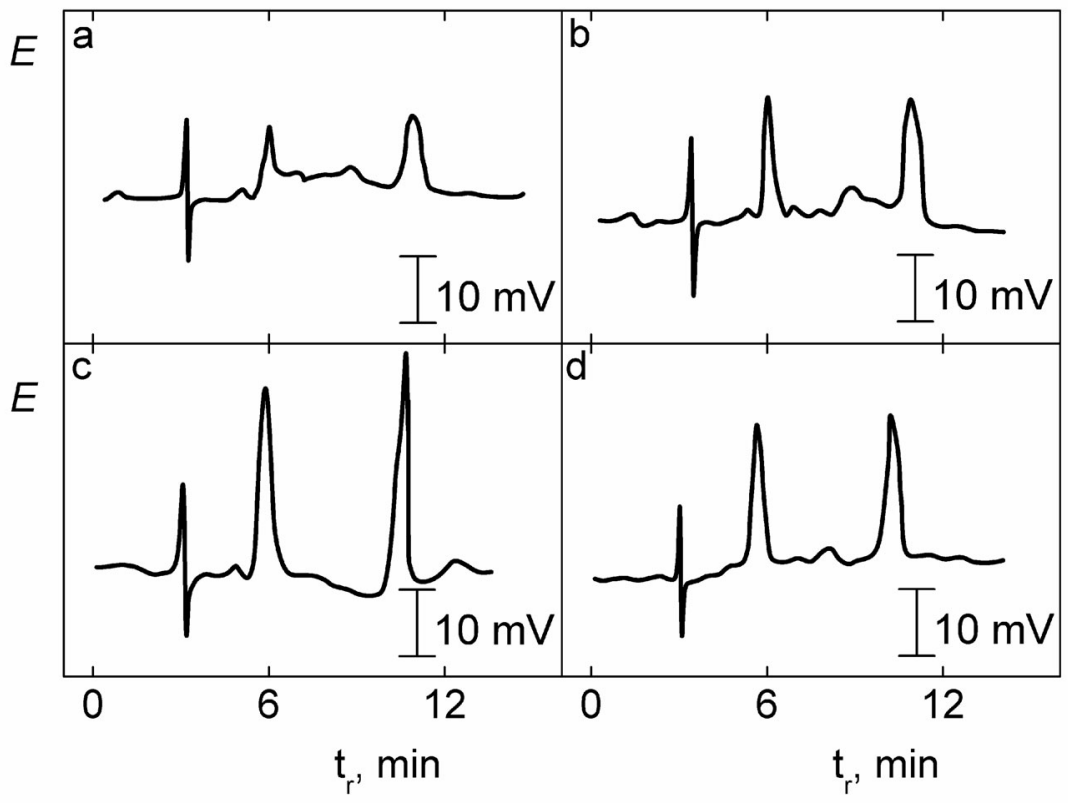

FIG. 9

Liquid chromatograms of aniline and phenylhydrazine at the following concentrations (in $\mathrm{mol} \mathrm{I}^{-1}$ ): $1 \times 10^{-4}(\mathrm{a}), 2 \times 10^{-4}$ (b), $3 \times 10^{-4}$ (c) and chromatogram of el ectrolysis product of DPT with initial concentration $5 \times 10^{-4}(\mathrm{~d})$ 
hydrazine $10.8 \mathrm{~min}$. In the chromatogram of the electrolysis product (Fig. 9, chromatogram d), both aniline and phenylhydrazine appear. On the basis of calibration curve of aniline and phenylhydrazine, given as the dependence of the peak area on the concentration, it was found that the relative ratio of aniline and phenylhydrazine in the electrolysis product is 55:45.

Considering that the slope of the $\mathrm{E}_{1 / 2}-\mathrm{pH}$ dependence at $\mathrm{pH} 6.5$ (Fig. 3) amounts to $0.056 \mathrm{~V}$ per $\mathrm{pH}$ unit and that the total number of exchanged electrons, which was obtained coulometrically, $n=4$, on the basis of the equation $\mathrm{dE} / \mathrm{dpH}=-2.303 \mathrm{mRT} / \alpha \mathrm{n}_{\mathrm{a}} \mathrm{F}$, it is found that the total number of protons participating in the electrochemical DPT reduction at the given $\mathrm{pH}$ value of the supporting electrolyte amounts to $m=3.8 \pm 0.3$.

On the basis of the presented results it can be concluded that 1,1-dimethyl-3-phenyltriazene is reduced on mercury electrode according to the scheme shown in Fig. 10.

Analytical Utilization of Polarographic Behavior of 1,1-Dimethyl-3-phenyltriazene

The supporting electrolyte found to be most suitable is a mixture of BR buffer and methanol with $\mathrm{pH}$ 6.50. In Figs 1 and 2 it can be seen that DPT is stable enough at the above $\mathrm{pH}$ and that it yields well defined and easily evaluated polarographic curves, with the highest current values for the given concentration. Using buffers containing 50 vol.\% methanol, linear calibration dependences for SDC and DP polarographic determinations of the investigated substance were obtained within the concentration range $1 \times 10^{-6}-1 \times 10^{-4} \mathrm{~mol} \mathrm{I}^{-1}$.

The sensitivity of the polarographic determination of the investigated substance is increased by five-fold dilution of BR buffer and decreasing the methanol content to $10 \mathrm{vol} . \%$, while $\mathrm{pH}$ values of the resulting solutions

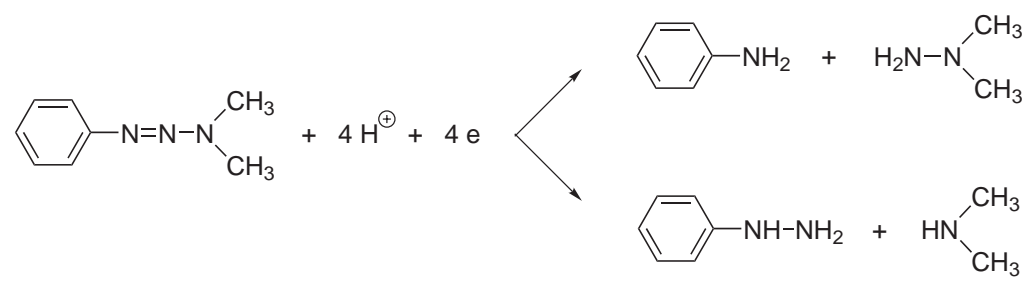

FIG. 10

The scheme of polarographic reduction of 1,1-dimethyl-3-phenyltriazene 
are maintained unchanged. Thus, the concentrations of the impurities present in the supporting electrolyte originating from impurities in the chemicals used for the electrolyte preparation decreased, which leads to smoother supporting electrolyte polarographic curves and an increase in the determination sensitivity. The methanol content decrease in polarographed solutions leads to a shift of half-wave potentials and DP peak potentials toward more positive values and it also increases the reversibility of the electrode process and thus it increases determination sensitivity. The use of the last mentioned medium as the supporting el ectrolyte enabled DP polarographic determinations in the concentration range $(1-10) \times 10^{-7} \mathrm{~mol} \mathrm{I}^{-1}$, as is presented in the Fig. 11.

The parameters of calibration straight lines - the slope $A$ and its standard deviation $S(A)$, the intercept $B$ and its standard deviation $S(B)$, the deviation of the experimental points from the cal culated straight line $\mathrm{S}_{\mathrm{I}, \mathrm{C}}$ and the correlation coefficient $r$ with the calculated limits of determination LOD for the above-described polarographic measurements - are given in Table I. The values of DPP peak potential $E_{p}$ are also given.

The possibility to further increase the sensitivity of the determination using differential pulse voltammetry and adsorptive stripping voltammetry at a hanging mercury drop electrode is under investigation.

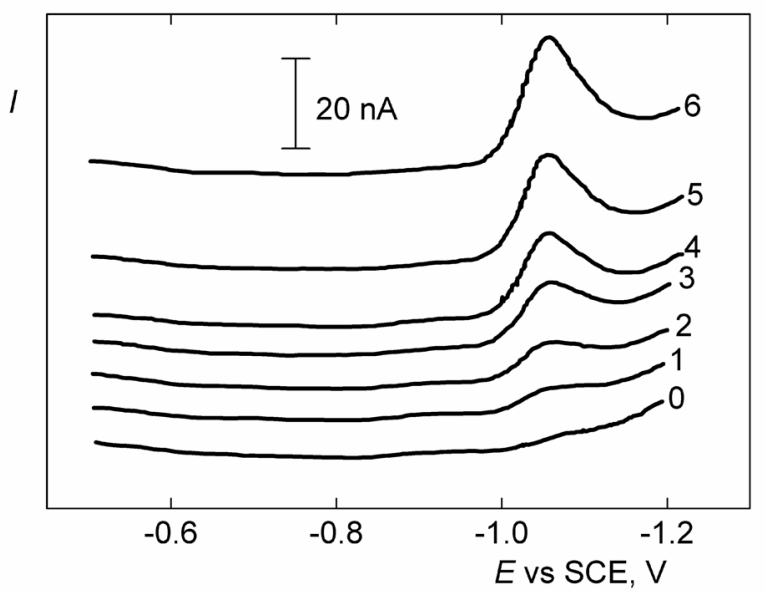

FIG. 11

DP polarograms of DPT in five-fold diluted BR buffer-methanol (9:1) medium, pH 6.50; concentration (in mol I-1): $1 \times 10^{-7}(1), 2 \times 10^{-7}(2), 4 \times 10^{-7}(3), 6 \times 10^{-7}(4), 8 \times 10^{-7}(5)$ and $10 \times 10^{-7}$ (6) 
TABLE I

Parameters of calibration straight lines and the values of DPP peak potential for polarographic determination of 1,1-dimethyl-3-phenyltriazene

\begin{tabular}{|c|c|c|c|c|c|c|c|}
\hline Method & $\begin{array}{l}\mathrm{C} \\
\mathrm{mol} \mathrm{I}\end{array}$ & $\mathrm{E}_{\mathrm{p}}$ & $\begin{array}{l}\mathrm{A} / \mathrm{S}(\mathrm{A})^{\mathrm{a}} \\
\mathrm{mA} \mid \mathrm{mol}^{-1}\end{array}$ & $\begin{array}{l}B / S(B)^{b} \\
n A\end{array}$ & $\begin{array}{l}\mathrm{S}_{1, \mathrm{C}^{\mathrm{c}}} \\
\mathrm{nA}\end{array}$ & $r$ & $\begin{array}{l}\text { LOD } \\
\mathrm{mol} \mathrm{I}^{-1}\end{array}$ \\
\hline $\mathrm{SDC}^{\mathrm{d}}$ & $(1-10) \times 10^{-5}$ & - & $10.0 / 0.2$ & $36 / 10$ & 15 & 0.9992 & \\
\hline$S D C^{d}$ & $(1-10) \times 10^{-6}$ & - & $10.3 / 0.2$ & $5 / 1$ & 1 & 0.9993 & $1 \times 10^{-6}$ \\
\hline$S D C^{e}$ & $(1-10) \times 10^{-6}$ & - & $11.3 / 0.4$ & $10 / 2$ & 3 & 0.9976 & $8 \times 10^{-7}$ \\
\hline DPP $^{d}$ & $(1-10) \times 10^{-5}$ & -1.130 & $16.9 / 0.2$ & $22 / 10$ & 12.5 & 0.9998 & \\
\hline DPP & $(1-10) \times 10^{-6}$ & -1.130 & $18.1 / 0.3$ & $-1 / 1$ & 2 & 0.9997 & $8 \times 10^{-7}$ \\
\hline DPPe & $(1-10) \times 10^{-6}$ & -1.060 & $22.2 / 0.9$ & $10 / 5$ & 6 & 0.9970 & \\
\hline DPPe & $(1-10) \times 10^{-7}$ & -1.055 & $24.3 / 0.5$ & $-0.6 / 0.3$ & 0.3 & 0.9994 & $1 \times 10^{-7}$ \\
\hline
\end{tabular}

${ }^{a}$ Slope/standard deviation. ${ }^{b}$ Intercept/standard deviation. ${ }^{c}$ Deviation of the experimental points from the calculated straight line. ${ }^{d}$ BR buffer-methanol (1:1) medium, pH 6.50. ${ }^{e}$ Five times diluted BR buffer-methanol (9:1) medium, pH 6.50.

This research was supported by the Ministry of Education, Youth and Sports of the Czech Republic (project No. LC 06035 and M SM 0021620857) and by the Ministry of Science and Environmental Protection of Serbia (project 142047).

\section{REFERENCES}

1. Burchenal J. H., Carter S. K.: Cancer (Philadelphia) 1972, 30, 1639.

2. Schmidt F. A., Hutchinson D. J.: Cancer Res. 1974, 34, 1917.

3. Le Fevre R. J. W., Liddicoet T. H.: J. Chem. Soc. 1951, 2743.

4. Matrka M., Rambousek V., Držková L., Zveřina V.: Cesk. Farm. 1978, 27, 299.

5. Iversen P. E. in: Encyclopedia of Electrochemistry of Elements - Organic Section (A. J. Bard and H. Lund, Eds), Vol. 13, Chap. 5, p. 209. Marcel Dekker, New York 1979.

6. Kazemifard G., Moattar F., Reisch J.: Acta Pharm. Yugosl. 1978, 28, 151.

7. Mejstř́k V., Ságner V., Držková L., Krampera F.: Cesk. Farm. 1985, 34, 51.

8. Ignjatović Lj. M., Barek J., Zima J., Marković D. A.: Anal. Chim. Acta 1993, 284, 413.

9. Barek J., Toubar S., Zima J.: Collect. Czech. Chem. Commun. 1991, 56, 2073.

10. Barek J., Fogg A. G.: Analyst 1992, 117, 751.

11. Ignjatović Lj. M., Barek J., Zima J., Marković D. A.: Mikrochim. Acta 1996, 122, 101.

12. Matrka M., Rambousek V., Remeš M., Zveřina V.: Cesk. Farm. 1978, 27, 70.

13. Paabo M., Robinson R. A., Bates R. G.: J. Am. Chem. Soc. 1965, 87, 415.

14. Gonzalez A. G., Pablos V., Asuero A. G.: Talanta 1992, 39, 91.

15. Beyermann K.: Organic Trace Analysis, p. 45. Ellis Horwood, Chichester 1984.

16. Zuman P.: Progress in Physical Organic Chemistry, Vol. 5, p. 99. John Wiley and Sons, New York 1967. 
17. Matrka M., Rambousek V., Zveřina V.: Cesk. Farm. 1978, 27, 346.

18. Thomas F. G., Henze G.: Introduction to Voltammetric Analysis - Theory and Practice. CSIRO Publishing, Collingwood 2001.

19. Mairanovskii S. G.: Talanta 1965, 12, 1299.

20. Vydra F., Štulík K., Julakova E.: Electrochemical Stripping Analysis. Ellis Horwood, Chichester 1976.

21. Greef R., Pat R., Peter L. M., Pletcher V., Robinson J.: Instrumental Methods in Electrochemistry, p. 178. Ellis Horwood, Chichester 1985.

22. Nicholson R. S., Shain I.: Anal. Chem. 1964, 36, 706.

23. Bard A. J., Faulkner L. R.: Electrochemical Methods - Fundamentals and Applications, p. 384. John Wiley and Sons, New York 1980. 